\title{
ELKS1 and $\mathrm{Ca}^{2+}$ channel subunit $\beta 4$ interact and colocalize at cerebellar synapses
}

\author{
Sara E. Billings, Gwenaëlle L. Clarke, and Hiroshi Nishimune \\ Department of Anatomy and Cell Biology, and Kansas Intellectual and Developmental Disabilities \\ Research Center, University of Kansas Medical School, Kansas City, KS 66160
}

\begin{abstract}
The cytoskeletal matrix of the active zone (CAZ) and synaptic voltage-dependent calcium channels (VDCCs) are both necessary components for the organization and regulation of synaptic vesicle release. Here we report a novel interaction between the CAZ protein ELKS1b and the VDCC subunit $\beta 4$ in the molecular layer of the cerebellum. We found that the two proteins coimmunoprecipitated using antibodies against each protein. Using fluorescent immunohistochemistry, we observed colocalization between ELKS1b and VDCC $\beta 4$ in the molecular layer of the cerebellum, suggesting that these proteins are both present in molecular layer synapses. Analysis of a P/Q-type VDCC knockout mouse $\left(\mathrm{Cacnala}^{-/}\right)$revealed that the localization of the VDCC $\beta 4$ subunit to the molecular layer was disrupted, although ELKS1b protein localization was not affected. The results demonstrate that these two proteins interact in vitro and colocalize in the cerebellum, and suggest that their interaction may play a role at the molecular layer synapses of the cerebellum.
\end{abstract}

\section{Keywords}

active zone; CAST; cytomatrix of the active zone; Erc1; voltage-dependent calcium channel

\section{Introduction}

Synaptic vesicle release results from the influx of calcium through VDCCs [1]. VDCCs consist of the pore-forming $\alpha$ subunit and auxiliary $\beta$ and $\alpha 2 \delta$ subunits [2]. When calcium enters the presynaptic terminal through a VDCC, the calcium concentration increases steeply in a small domain immediately surrounding the VDCC [3]. As it is this increase in calcium concentration that triggers synaptic vesicle release [1], calcium channels, synaptic vesicles and regulatory proteins need to be in close proximity, and are therefore likely to interact.

Correspondence and request for reprints: Hiroshi Nishimune, Ph.D., Address: University of Kansas Medical Center, Department of Anatomy and Cell Biology, 3901 Rainbow Blvd., MS 3051, KLSIC Rm. 2073, Kansas City, KS 66160, USA hnishimune@ kumc.edu. Publisher's Disclaimer: This is a PDF file of an unedited manuscript that has been accepted for publication. As a service to our customers we are providing this early version of the manuscript. The manuscript will undergo copyediting, typesetting, and review of the resulting proof before it is published in its final citable form. Please note that during the production process errors may be discovered which could affect the content, and all legal disclaimers that apply to the journal pertain.

Conflicts of interest

None declared.

Authors contributions to the study: S.E.B. and H.N. planned the study. S.E.B. and G.L.C. performed the experiments and S.E.B. analyzed the data. S.E.B. and H.N. wrote the manuscript. 
Some of these regulatory proteins are part of the CAZ, a densely interlinked network of proteins that overlies the presynaptic membrane [4]. Vertebrate active zone proteins include Bassoon, Piccolo, Muncs, RIMs, and the ELKS/CAST/Rab6 interacting protein family [4]. Many interconnections among CAZ proteins have been described, as exemplified by the ELKS/CAST/Rab6 interacting protein family, which links to all known active zone proteins $[4,5]$.

In contrast to the extensive knowledge about interconnections between CAZ proteins, only a few interactions have been reported between CAZ proteins and VDCCs that bring these complexes into close proximity [6-11]. Our previous report detected interactions between ELKS2/CAST and VDCC $\beta$ subunits [10]. However, the interaction of ELKS1 and VDCC subunits has not been described.

ELKS proteins are encoded by two separate genes: ELKS1 and ELKS2 [12]. ELKS1b, the synaptic splice variant of ELKS1, is highly expressed in the cerebellum, where there is little to no ELKS2 expression [13,14]. Thus, the cerebellum is an ideal place to study the role of a possible interaction between ELKS1b and VDCCs. In the cerebellum, VDCC $\beta 4$ is the most highly expressed $\beta$ subunit [15]. Therefore, we analyzed the interaction between ELKS1b and VDCC $\beta 4$ to determine whether they might connect the CAZ complex to VDCCs and contribute to active zone organization.

\section{Methods}

Animals

Cacnala $^{-/-}$mice on a C57BL6/J background were previously generated [16]. Animal procedures were in accordance with the regulations of the University of Kansas Medical Center.

\section{Antibodies}

The following antibodies were used: anti-VDCC $\beta 4$ (Neuromab, Davis, CA), anti-ELKS1b/2 (anti-Erc1b/2, Synaptic Systems, Göttingen, Germany), anti-Flag (Sigma, St. Louis, MO), and secondary antibodies conjugated to Alexa Fluor 488, 568 (Invitrogen), or alkaline phosphatase (Jackson ImmunoResearch Laboratories, Inc., West Grove, PA).

\section{Co-immunoprecipitation}

Methods for co-immunoprecipitation using anti-VDCC $\beta 4$ antibody were described previously [10]. Full length ELKS1b was subcloned from the cDNA KIAA 1081 (Kazusa DNA research Institute, Kisarazu, Chiba, Japan) and expressed as a Flag-tagged fusion protein. The expression plasmid for full length VDCC $\beta 4$ was obtained from Origene (MC201619; Rockville, MD). HEK293T cells were transfected with these plasmids and lysed by pipetting in Triton-X 100 lysis buffer $(150 \mathrm{mM} \mathrm{NaCl}, 0.5 \mathrm{mM}$ EDTA, $1 \mathrm{mM}$ DTT, $1 \% \mathrm{vol} / \mathrm{vol}$ Triton-X 100, protease inhibitor tablet (Roche), $20 \mathrm{mM}$ Tris, $\mathrm{pH}$ 7.4). For the reverse co-immunoprecipitation, Flag-ELKS1 was mixed with anti-Flag antibody and protein G-conjugated magnetic beads (Invitrogen), and then incubated with VDCC $\beta 4$ lysate for two hours at $4^{\circ} \mathrm{C}$.

\section{Immunohistochemistry}

Methods for immunohistochemistry were described previously [10]. Mice were euthanized with isoflurane at postnatal day 19 and perfused with phosphate-buffered saline (PBS) followed by $4 \%$ paraformaldehyde (PFA) in PBS. Brains were post-fixed in 4\% PFA and cryoprotected in $20 \%$ sucrose/PBS. Twenty- $\mu$ m-thick cryostat sections were blocked in $2 \%$ bovine serum albumin (Sigma), 2\% normal goat serum (GIBCO), 0.1\% Triton X-100 
(Sigma) in PBS. The sections were incubated overnight at $4{ }^{\circ} \mathrm{C}$ with anti-VDCC $\beta 4$ and antiELKS1b/2 antibodies diluted in blocking solution, then incubated with secondary antibodies.

\section{Co-localization analysis}

Single optical planes were obtained from the molecular layer of the cerebellum of three wild-type animals using a Nikon C1Si confocal microscope [100× Apo TIRF lens Numerical aperture $(\mathrm{NA})=1.49$ ]. $\mathrm{XY}$ pixel size was $69.1 \mathrm{~nm}$.

An iterative thresholding method was adapted to identify puncta [17]. Image thresholds were determined using the automatic threshold function in ImageJ. Using the Analyze Particle function, puncta of a restricted size range were identified at each of the threshold levels between 255 and the automatic threshold grayscale value. The puncta size range was restricted to between $0.095 \mu \mathrm{m}^{2}$ and $0.285 \mu \mathrm{m}^{2}$ for the following reasons: The lower value $\left(0.095 \mu \mathrm{m}^{2}\right)$ represents the area of a circle with the diameter of the average electron microscopy active zone length of adult mouse cerebellar parallel fiber-Purkinje cell synapses $(0.348 \pm 12 \mu \mathrm{m})$ [18]. The upper value $\left(0.285 \mu \mathrm{m}^{2}\right)$ represents the size below which ninetyfive percent of signals for synaptic antigens will fall when imaged by light microscopy [19]. The regions of interest (ROI) generated by this process were combined and a mask of the combined ROI was created, such that each puncta identified was represented by a particle on the mask.

The overlapping area between ELKS1b and VDCC $\beta 4$ was analyzed by dividing the area of colocalized signals by the total area of ELKS1b signal. The number of colocalizing puncta was analyzed by counting the number of ELKS1b puncta that overlapped with at least 0.05 or $0.023 \mu \mathrm{m}^{2}$ of the VDCC $\beta 4$ puncta and dividing that number by the total number of ELKS1b puncta.

\section{Fluorescent intensity quantification}

Epifluorescent images were obtained on a Nikon 80i microscope [Plan Apo 20× lens, NA = 0.75]. Three pairs of wild-type and knockout littermates were evaluated, and similar areas were imaged for each pair. Four to five areas of the cerebellum were imaged, measured and averaged for each animal. The mean fluorescent intensity of the molecular layer was measured in ImageJ using a box of fixed width ( 230 pixels) that extended from the pia to the tops of the Purkinje cells. The mean fluorescent intensity of the granule cell layer was measured using a box of 230 pixels squared.

\section{Statistics}

We used a paired t-test when comparing wild-type and Cacnala ${ }^{-1-}$ because the animals were littermates and were prepared and analyzed in pairs. Data show mean \pm SEM.

\section{Results}

We tested the binding of ELKS1b and VDCC $\beta 4$ by performing co-immunoprecipitation with heterologously expressed protein lysates. Flag-ELKS1b protein co-immunoprecipitated with VDCC $\beta 4$ (Fig. 1A). To confirm the specificity of this interaction, we performed the co-immunoprecipitation in reverse, using an anti-Flag antibody against the Flag-ELKS1b protein. We detected co-immunoprecipitation of VDCC $\beta 4$, at the same molecular weight as the input VDCC $\beta 4$ band (Fig. 1B). We did not observe co-immunoprecipitation in the control reactions when the bait protein was omitted (Fig. 1A and 1B; HEK). These data indicated that ELKS1b and VDCC $\beta 4$ form a protein complex in vitro. 
We next analyzed whether ELKS1 and VDCC $\beta 4$ colocalize by performing immunohistochemistry on sagittal mouse cerebellar sections. Consistent with previous work $[15,20]$, ELKS1b/2 and VDCC $\beta 4$ antibodies both stained the molecular layer. The ELKS1b/ 2 antibody recognizes the shared C-terminus of ELKS1b and ELKS2. As ELKS1 is highly expressed in the cerebellum, whereas ELKS2 is below the western blot detection level [14], the majority of signal observed here is likely to represent ELKS1b staining. While VDCC $\beta 4$ staining was highly concentrated in the molecular layer, ELKS1b/2 staining was found at similar intensities in both the molecular layer and the granule cell layer (Fig. 3A, top panels).

We then acquired confocal images of the molecular layer to analyze colocalization. ELKS1b/2 and VDCC $\beta 4$ staining revealed many small, closely packed puncta distributed throughout the molecular layer (Fig. 2A-C), which is consistent with the distribution of synapses between granule cells and Purkinje cells [21]. We created masks that demarcated the puncta for each antigen (Fig. $2 \mathrm{D}$ and E). When the overlapping area was analyzed, $16.35 \pm 1.06 \%$ of the ELKS1b/2 signal overlapped with the VDCC $\beta 4$ signal. When the number of colocalizing puncta was analyzed, $25.06 \pm 0.89 \%$ of the ELKS1b/2 puncta overlapped with VDCC $\beta 4$ puncta by at least $0.05 \mu \mathrm{m}^{2}$, and $45.48 \pm 1.45 \%$ overlapped by at least $0.023 \mu \mathrm{m}^{2}$. These results revealed a moderate overlap between ELKS1b/2 and VDCC $\beta 4$ in the molecular layer and suggested that ELKS1b/2 and VDCC $\beta 4$ puncta are often found in close proximity to each other.

VDCC $\beta 4$ is the preferred $\beta$ subunit of VDCC $\alpha 1 \mathrm{~A}\left(\mathrm{Ca}_{\mathrm{v}} 2.1\right)$ [22], which forms the P/Q-type VDCC [2]. We hypothesized that the loss of VDCC $\alpha 1 \mathrm{~A}$ would perturb the localization of VDCC $\beta 4$ to the molecular layer, as $\beta$ subunits are dependent on $\alpha$ subunits for targeting to the plasma membrane [23]. Therefore, performing immunohistochemistry for VDCC $\beta 4$ and ELKS1b/2 on P/Q-type VDCC knockout mice $\left(\right.$ Cacnala $^{-/}$) allowed us to probe the potential in vivo interaction between VDCC $\beta 4$ and ELKS1. We measured the fluorescence intensity for both VDCC $\beta 4$ and ELKS1b/2 in the molecular layer and in the granule cell layer of Cacnala ${ }^{-/-}$and wild-type littermates.

The signal intensity of VDCC $\beta 4$ decreased in the molecular layer of $\mathrm{Cacnala}^{-/-}$cerebella (Fig. 3A, B; wild-type: $12.38 \pm 0.13$ mean fluorescence intensity in arbitrary units (A.U.); Cacnala $a^{-/-}: 9.31 \pm 0.39$ A.U., $\left.\mathrm{p}=0.02\right)$. In contrast, there was no significant difference in VDCC $\beta 4$ in the granule cell layer (wild-type: $9.77 \pm 0.44$ A.U.; Cacnala ${ }^{-1-}: 8.96 \pm 0.75$ A.U., $p=0.23$ ). Additionally, Purkinje cell bodies appeared to have increased VDCC $\beta 4$ signal in the Cacnala $^{-1}$. The reduction in VDCC $\beta 4$ intensity in the molecular layer suggested that VDCC $\beta 4$ localization is perturbed by the loss of the $\alpha 1 \mathrm{~A}$ subunit.

However, ELKS1b/2 mean fluorescent intensity was unchanged in both the molecular layer (Fig. 3A, C; wild-type: $11.79 \pm 0.95$ A.U.; Cacnala ${ }^{-1-}: 11.95 \pm 0.82$ A.U., $p=0.74$ ) and the granule cell layer (wild-type: $8.08 \pm 1.00$ A.U.; Cacnala ${ }^{-/-}: 8.14 \pm 0.55$ A.U. p $=0.95$ ) of Cacnala $^{-/-}$cerebella (Fig. 3A). These data suggest that ELKS1 is not dependent on VDCC $\beta 4$ for trafficking into the molecular layer.

\section{Discussion}

In this study, we have investigated the possibility that VDCC $\beta 4$ and ELKS1 connect the calcium channel and CAZ complexes in the cerebellum. We detected an interaction between VDCC $\beta 4$ and ELKS1b by co-immunoprecipitation and observed moderate colocalization between these two proteins in the molecular layer of the cerebellum using fluorescent immunohistochemistry. These results suggest that VDCC $\beta 4$ and ELKS1b interact in 
molecular layer synapses and represent a novel connection between calcium channel and CAZ complexes.

VDCC $\beta 4$ and ELKS1 puncta tended to reside next to each other, as shown by the high percentage of puncta that overlapped by 0.023 or $0.05 \mu \mathrm{m}^{2}$. However, the overlap of the total area between VDCC $\beta 4$ and ELKS1b was moderate. One possible reason is that although ELKS1b has been described as an active zone protein, it may be less tightly associated to the CAZ than ELKS2 [13].

In order to further probe the relationship between VDCC $\beta 4$ and ELKS1, we performed immunohistochemistry for VDCC $\beta 4$ and ELKS1b on cerebella of Cacnala ${ }^{-1-}$ mice. We found a decrease in signal intensity of VDCC $\beta 4$ in the molecular layer. This is the first report of an attenuation of VDCC $\beta 4$ in $\mathrm{Cacnala}^{-/}$mice. This defect could be due to reduced transport of VDCC $\beta 4$ into the molecular layer, because VDCC $\beta$ subunits are dependent on VDCC $\alpha$ subunits for plasma membrane targeting [23]. The reduction of VDCC $\beta 4$ in the molecular layer in spite of the expression of other VDCC $\alpha$ subunits in the cerebellum $[15,16]$ suggests a specific interaction between VDCC $\alpha 1 \mathrm{~A}$ and $\beta 4$ subunits that cannot be compensated for by other VDCC $\alpha$ subunits.

While VDCC $\beta 4$ decreased in the molecular layer in Cacnala $^{-1-}$ mice, ELKS1b was unchanged, suggesting that ELKS1b does not rely on VDCC $\beta 4$ for trafficking into the molecular layer. However, the interactions between ELKS1b and other CAZ proteins $[20,24]$ may stabilize ELKS1b in the absence of VDCC $\beta 4$. Similarly, liprin- $\alpha$, which interacts directly with ELKS2 $\alpha$ [25], does not decrease in the synaptosomal fraction in ELKS $2 \alpha$ knockout mice [14], showing that the loss of a single interaction partner was not sufficient to change the localization of liprin- $\alpha$.

In conclusion, we have demonstrated an interaction between VDCC $\beta 4$ and ELKS1b and moderate colocalization in the molecular layer of the cerebellum, suggesting a synaptic function for a VDCC $\beta 4$-ELKS1b interaction such as linking VDCCs to the CAZ.

\section{Acknowledgments}

We thank J. Chen and B. Ackley for manuscript editing. This work was supported by grants from the NIH-NCRR (RR024214) and Whitehall foundation to H.N., and by the Kansas IDDRC (NICHD HD002528).

\section{References}

1. Katz B. Neural transmitter release: from quantal secretion to exocytosis and beyond. The Fenn Lecture. J Neurocytol. 1996; 25:677-686. [PubMed: 9023717]

2. Catterall WA. Structure and regulation of voltage-gated Ca2+ channels. Annu Rev Cell Dev Biol. 2000; 16:521-555. [PubMed: 11031246]

3. Neher E. Vesicle pools and $\mathrm{Ca} 2+$ microdomains: new tools for understanding their roles in neurotransmitter release. Neuron. 1998; 20:389-399. [PubMed: 9539117]

4. Schoch S, Gundelfinger ED. Molecular organization of the presynaptic active zone. Cell Tissue Res. 2006; 326:379-391. [PubMed: 16865347]

5. Hida Y, Ohtsuka T. CAST and ELKS Proteins: Structural and Functional Determinants of the Presynaptic Active Zone. J Biochem. 2010

6. Coppola T, Magnin-Luthi S, Perret-Menoud V, Gattesco S, Schiavo G, Regazzi R. Direct interaction of the Rab3 effector RIM with Ca2+ channels, SNAP-25, and synaptotagmin. J Biol Chem. 2001; 276:32756-32762. [PubMed: 11438518]

7. Shibasaki T, Sunaga Y, Fujimoto K, Kashima Y, Seino S. Interaction of ATP sensor, cAMP sensor, $\mathrm{Ca} 2+$ sensor, and voltage-dependent $\mathrm{Ca} 2+$ channel in insulin granule exocytosis. J Biol Chem. 2004; 279:7956-7961. [PubMed: 14660679] 
8. Kiyonaka S, Wakamori M, Miki T, Uriu Y, Nonaka M, Bito H, et al. RIM1 confers sustained activity and neurotransmitter vesicle anchoring to presynaptic $\mathrm{Ca} 2+$ channels. Nat Neurosci. 2007; 10:691-701. [PubMed: 17496890]

9. Uriu Y, Kiyonaka S, Miki T, Yagi M, Akiyama S, Mori E, et al. Rab3-interacting Molecule g isoforms lacking the Rab3-binding domain induce long-lasting currents but block neurotransmitter vesicle-anchoring in voltage-dependent P/Q-type Ca2+ channels. J Biol Chem. 2010; 285:2175021767. [PubMed: 20452978]

10. Chen J, Billings SE, Nishimune H. Calcium Channels Link the Muscle-Derived Synapse Organizer Laminin beta2 to Bassoon and CAST/Erc2 to Organize Presynaptic Active Zones. J Neurosci. 2011; 31:512-525. [PubMed: 21228161]

11. Kaeser PS, Deng L, Wang Y, Dulubova I, Liu X, Rizo J, et al. RIM Proteins Tether Ca2+ Channels to Presynaptic Active Zones via a Direct PDZ-Domain Interaction. Cell. 2011; 144:282-295. [PubMed: 21241895]

12. Wang Y, Liu X, Biederer T, Südhof TC. A family of RIM-binding proteins regulated by alternative splicing: Implications for the genesis of synaptic active zones. Proc Natl Acad Sci U S A. 2002; 99:14464-14469. [PubMed: 12391317]

13. Ko J, Yoon C, Piccoli G, Chung HS, Kim K, Lee J-R, et al. Organization of the Presynaptic Active Zone by ERC2/CAST1-Dependent Clustering of the Tandem PDZ Protein Syntenin-1. J Neurosci. 2006; 26:963-970. [PubMed: 16421316]

14. Kaeser PS, Deng L, Ch·vez AE, Liu X, Castillo PE, Südhof TC. ELKS2alpha/CAST Deletion Selectively Increases Neurotransmitter Release at Inhibitory Synapses. Neuron. 2009; 64:227-239. [PubMed: 19874790]

15. Ludwig A, Flockerzi V, Hofmann F. Regional Expression and Cellular Localization of the alpha1 and beta Subunit of High Voltage-Activated Calcium Channels in Rat Brain. J Neurosci. 1997; 17:1339-1349. [PubMed: 9006977]

16. Jun K, Piedras-Renteria ES, Smith SM, Wheeler DB, Lee SB, Lee TG, et al. Ablation of P/Q-type $\mathrm{Ca}(2+)$ channel currents, altered synaptic transmission, and progressive ataxia in mice lacking the alpha(1A)-subunit. Proc Natl Acad Sci U S A. 1999; 96:15245-15250. [PubMed: 10611370]

17. Fish KN, Sweet RA, Deo AJ, Lewis DA. An automated segmentation methodology for quantifying immunoreactive puncta number and fluorescence intensity in tissue sections. Brain Res. 2008; 1240:62-72. [PubMed: 18793619]

18. Takeuchi T, Miyazaki T, Watanabe M, Mori H, Sakimura K, Mishina M. Control of Synaptic Connection by Glutamate Receptor delta2 in the Adult Cerebellum. J Neurosci. 2005; 25:21462156. [PubMed: 15728855]

19. Mishchenko Y. On optical detection of densely labeled synapses in neuropil and mapping connectivity with combinatorially multiplexed fluorescent synaptic markers. PLoS One. 2010; 5:e8853. [PubMed: 20107507]

20. Deguchi-Tawarada M, Inoue E, Takao-Rikitsu E, Inoue M, Ohtsuka T, Takai Y. CAST2: identification and characterization of a protein structurally related to the presynaptic cytomatrix protein CAST. Genes to Cells. 2004; 9:15-23. [PubMed: 14723704]

21. Palay, S.; Chan-Palay, V. Cerebellar cortex: cytology and organization. New York: Springer; 1974. p. 63-99.

22. Muller C, Haupt A, Bildl W, Schindler J, Knaus H, Meissner M, et al. Quantitative proteomics of the Cav2 channel nano-environments in the mammalian brain. Proc Natl Acad Sci U S A. 2010; 107:14950-14957. [PubMed: 20668236]

23. Gao T, Chien AJ, Hosey MM. Complexes of the alpha1C and beta subunits generate the necessary signal for membrane targeting of class C L-type calcium channels. J Biol Chem. 1999; 274:21372144. [PubMed: 9890976]

24. Ohara-Imaizumi M, Ohtsuka T, Matsushima S, Akimoto Y, Nishiwaki C, Nakamichi Y, et al. ELKS, a protein structurally related to the active zone-associated protein CAST, is expressed in pancreatic beta cells and functions in insulin exocytosis: interaction of ELKS with exocytotic machinery analyzed by total internal reflection fluorescence microscopy. Mol Biol Cell. 2005; 16:3289-3300. [PubMed: 15888548] 
25. Ko J, Na M, Kim S, Lee JR, Kim E. Interaction of the ERC family of RIM-binding proteins with the liprin-alpha family of multidomain proteins. J Biol Chem. 2003; 278:42377-42385. [PubMed: 12923177] 

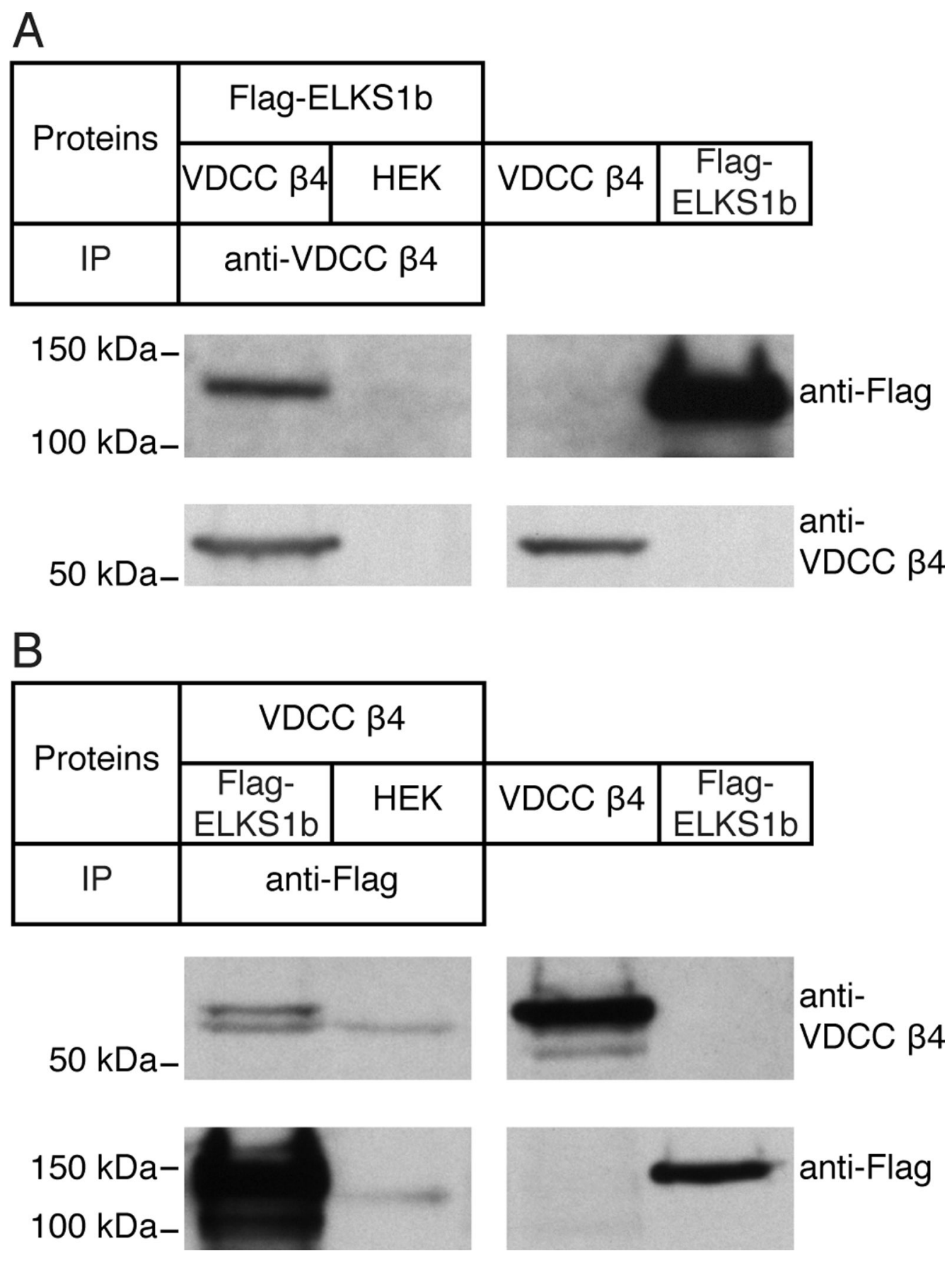

Figure 1.

VDCC $\beta 4$ and ELKS1b interact. Human embryonic kidney (HEK) cell lysates containing heterologously expressed proteins were incubated together and then immunoprecipitated with either anti-VDCC $\beta 4$ or anti-Flag antibody. $\boldsymbol{A}$, Flag-ELKS1b co-immunoprecipitated with VDCC $\beta 4$ when an anti-VDCC $\beta 4$ antibody was used. $\boldsymbol{B}$, In the reverse coimmunoprecipitation, VDCC $\beta 4$ co-immunoprecipitated with Flag-ELKS1b when an antiFlag antibody was used. The lower molecular weight band observed in both lanes is a nonspecific detection of the immunoprecipitation antibody. Input controls (right panels) indicate expected molecular weights. 


\section{VDCC $\beta 4$}
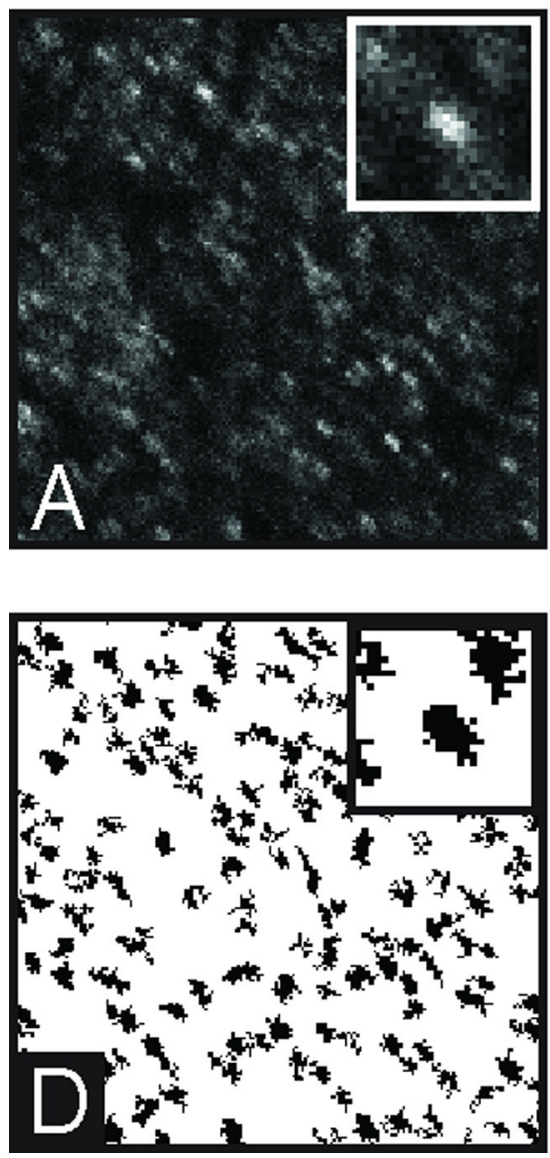

ELKS1b/2
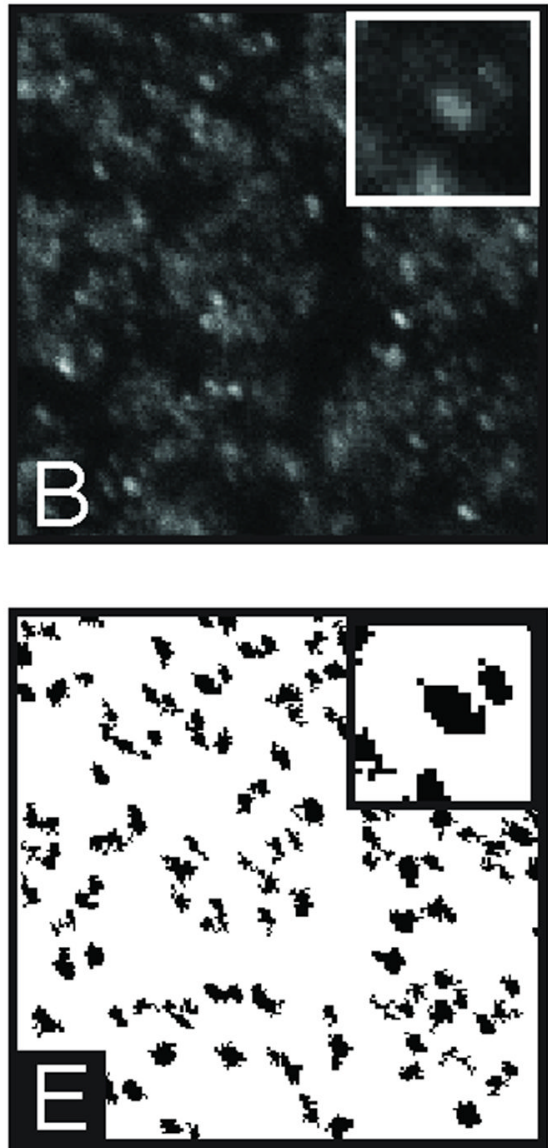

VDCC $\beta 4$

ELKS1b/2
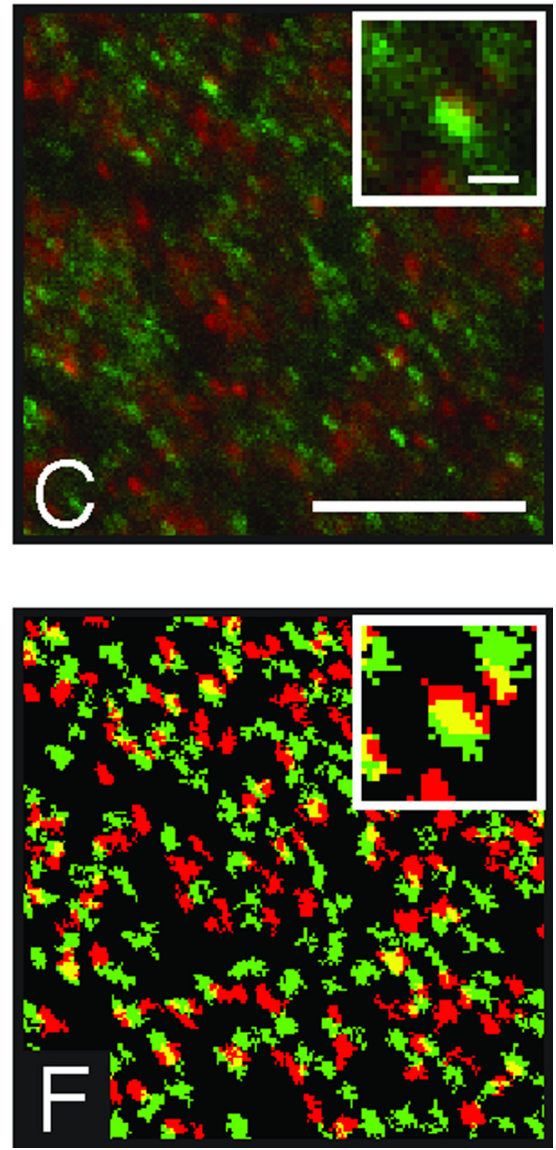

Figure 2.

VDCC $\beta 4$ and ELKS1b/2 colocalize in the molecular layer of the cerebellum. Single optical planes were acquired by confocal microscopy after fluorescent immunohistochemistry with antibodies against VDCC $\beta 4$ and $\operatorname{ELKS1b} / 2(\boldsymbol{A}, \boldsymbol{B})$, and iterative threshold masks of the puncta for each image were created $(\boldsymbol{D}, \boldsymbol{E})$. The merged image $(\boldsymbol{C})$ and mask $(\boldsymbol{F})$ show VDCC $\beta 4$ in green and ELKS1b/2 in red and their colocalization in yellow. Scale bar $=5$ $\mu \mathrm{m}$. Insets show a magnified area of the images. Scale bar $=500 \mathrm{~nm}$. 

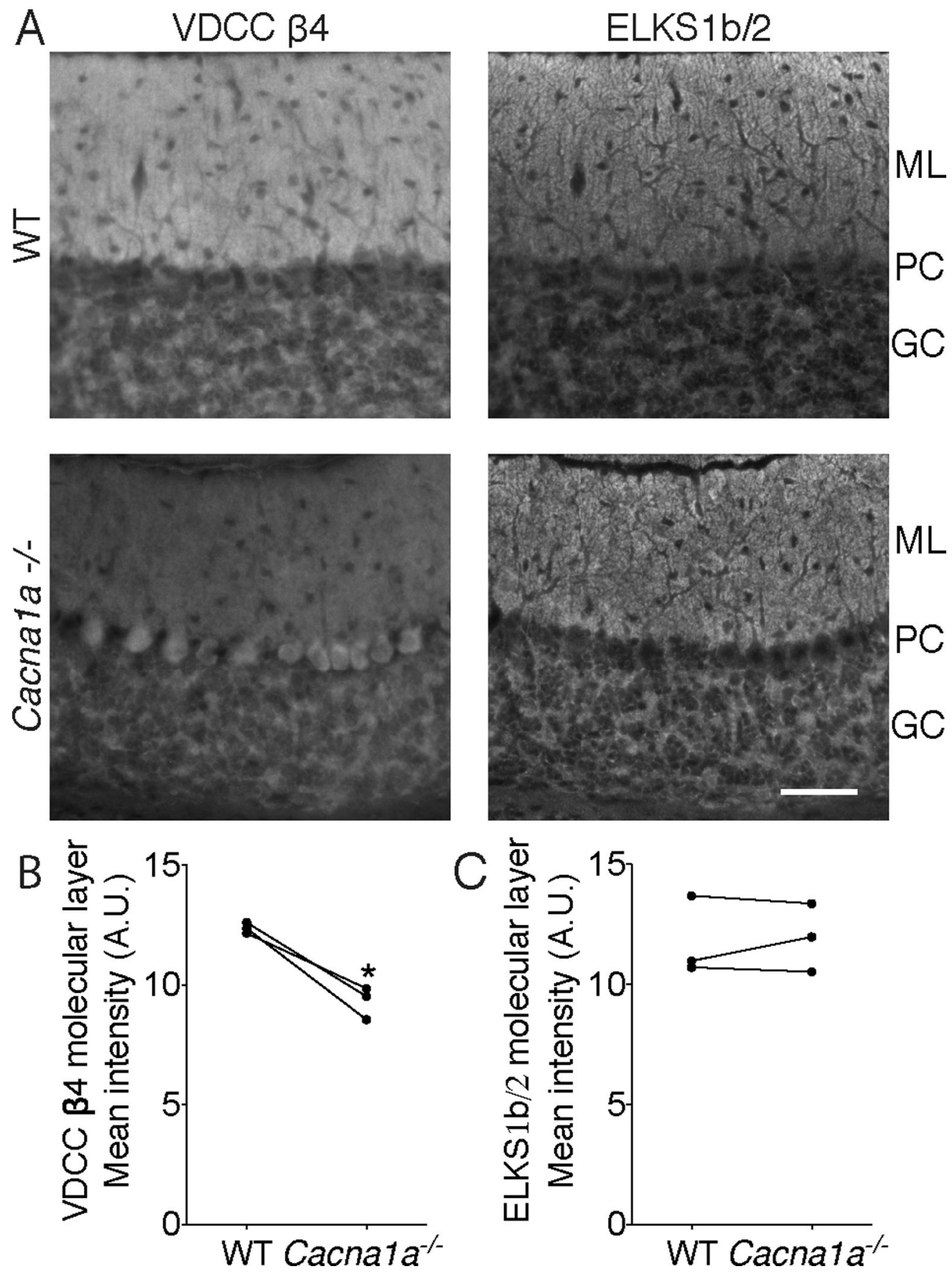

Figure 3.

VDCC $\beta 4$ protein is reduced in the molecular layer of Cacnala ${ }^{-/-}$cerebellum. Wild-type (WT) and Cacnala ${ }^{-1-}$ cerebella were stained for VDCC $\beta 4$ and ELKS1b/2 using fluorescent immunohistochemistry. The mean fluorescent intensity of VDCC $\beta 4$ decreased in the molecular layer (ML in $\boldsymbol{A}, \boldsymbol{B}$ ) but not the granule cell layer (GC in $\boldsymbol{A}$ ) of Cacnala ${ }^{-/-}$ cerebellum at postnatal day 19 (n=3 animal pairs), whereas ELKS1b/2 was not changed in Cacnala $^{-/-}$cerebellum (ML in A, C). Purkinje cells (PC). The asterisk indicates a p-value < 0.05. Scale bar $=50 \mu \mathrm{m}$. 